$c 4$

Commercialization will

need to

address

long-term

stability and

consistent

mass

manufacture

$\Rightarrow$ CHEMICAL SENSING

\title{
Wacker mole of ethylene
}

Ethylene is not only a ubiquitous building block in industry but also a hormone central to plant development. Formed in plants from 1-aminocyclopropanecarboxylic acid, ethylene binds to $\mathrm{Cu}^{\mathrm{I}}$ proteins and triggers ripening, blossoming and senescence - processes we must time properly so fruits and flowers get to us in good shape. Despite the importance of these processes, we lack a good ethylene sensor to monitor the developmental state of our produce, a lot of which unnecessarily spoils during supply. This challenge has now been addressed by Timothy Swager and colleagues, who describe in ACS Central Science a sensitive system that quantifies ethylene by catalytically converting it to acetaldehyde.

Plant development can be associated with ethylene concentrations on the order of parts per billion, a level of sensitivity that online measurements have yet to achieve. If that were not enough of a problem, practical systems must also be robust and give rapid and selective responses for ethylene in the presence of other volatile organics. By no means new to this game, Swager's team had previously developed a sensor comprising two electrodes spanned by a matrix of single-walled carbon nanotubes and $\mathrm{C} \mathrm{Cu}^{\mathrm{I}}$ complex, all atop a glass substrate. As is the case in nature, the low-valent metal sites reversibly bind ethylene, here signalling the event by lowering the electrical current through the nanotubes. However, this chemiresistive sensor proved neither robust nor apt to quantify ethylene at levels below $500 \mathrm{ppb}$.

The quest for greater sensitivity saw Swager's team replace their reversible binding strategy in favour of subjecting ethylene to catalytic Wacker oxidation, a Pd-catalyzed reaction that consumes $\mathrm{O}_{2}$ to afford acetaldehyde. The team once more prepared a chemiresistor circuit but this time decorated their nanotubes with 4-pyridyl groups and replaced the $\mathrm{Cu}^{\mathrm{I}}$ complex with a catalytic mixture of $\left[\mathrm{PdCl}_{2}(\mathrm{NCPh})_{2}\right]$, ${ }^{n} \mathrm{Bu}_{4} \mathrm{~N}\left[\mathrm{NO}_{2}\right]$ and $\mathrm{BnOH}$. This mixture differs from the typical Wacker oxidation system, which instead features $\mathrm{AgNO}_{2}$ as the source of nitrite. "Here we use a new variant

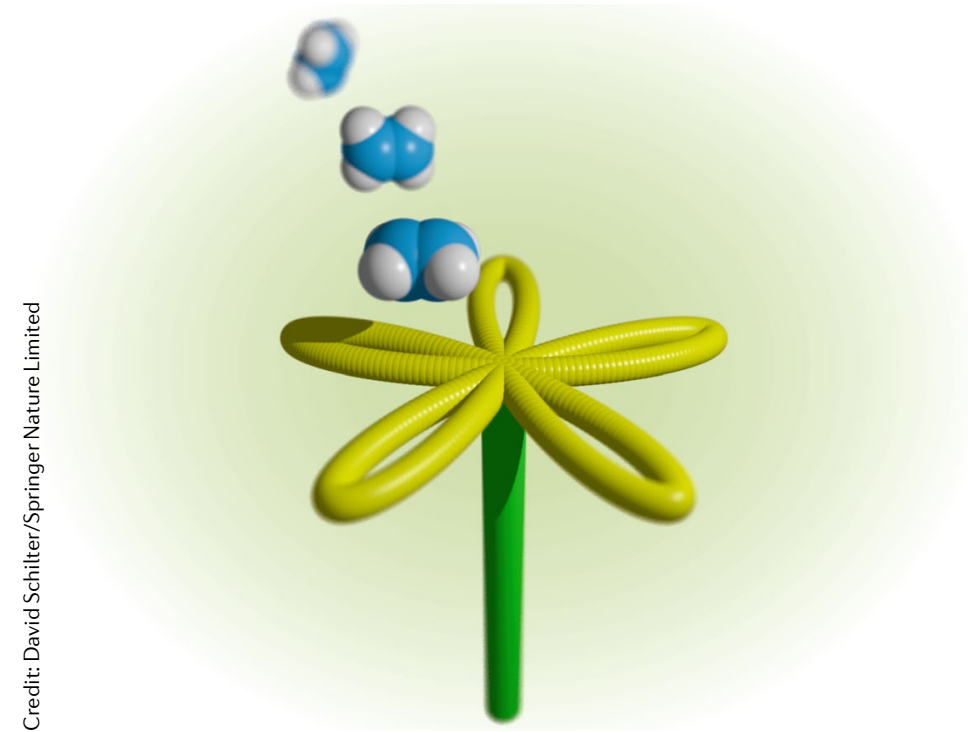

of the reaction optimized for our non-volatile solvent," notes Swager. In the resting state, the nanotubes are p-type semiconductors that feature Pd ${ }^{\mathrm{II}}$ sites bound to 4-pyridyl groups. Each $\mathrm{Pd}^{\mathrm{II}}$ site can bind ethylene and $\mathrm{H}_{2} \mathrm{O}$ to generate acetaldehyde and convert into a $\mathrm{Pd}^{0}$ complex. This electron-rich site now engages in electron-transfer with the nanotubes to attenuate their p-type character and give a measurable decrease in conductance. The $\mathrm{Pd}^{0}$ state can re-enter the cycle on aerobic oxidation, which curiously proceeds even in the absence of $\mathrm{Cu}^{\mathrm{II}}$, an ingredient in the classic Wacker system and a typical $\mathrm{O}_{2}$ reduction electrocatalyst. Thus, although the new sensor generates acetaldehyde, it is not this product but rather its mechanism of formation that is quantified. The system consumes only negligible amounts of ethylene, so as not to perturb the environment around the plant or to generate too much toxic acetaldehyde.

How does the new sensor perform? Within seconds of exposure, the sensor can quantify ethylene down to $15 \mathrm{ppb}$ - a low value that brings relevance to this chemiresistor, which Swager's team demonstrated by monitoring carnation and lisianthus flowers. While carnations bloomed within a day, the lisianthus flowers took up to a week, as reflected by the latter flowers registering slower but more sustained ethylene emission. Such a sensor will allow us to make well-informed decisions regarding plant supply and tell us whether or not we should accelerate development with exogenous ethylene. "Commercialization will need to address long-term stability and consistent mass manufacture," notes Swager. It seems apparent that these challenges will not stop the team from realizing the blossoming of their new sensor technology.

David Schilter 